\title{
Diabetes, Smoking, Alcohol Use, and Family History of Cancer as Risk Factors for Pancreatic Neuroendocrine Tumors: A Systematic Review and Meta-Analysis
}

\author{
Sven-Petter Haugvik ${ }^{\mathrm{a}, \mathrm{b}}$ Per Hedenström ${ }^{c}$ Emilie Korsæth $^{\mathrm{b}}$ Roberto Valente $^{\mathrm{d}}$ \\ Alastair Hayes $^{f}$ Darko Siukag Patrick Maisonneuve ${ }^{\mathrm{e}}$ Ivar Prydz Gladhauga, b \\ Björn Lindkvist ${ }^{c}$ Gabriele Capurso $^{d}$

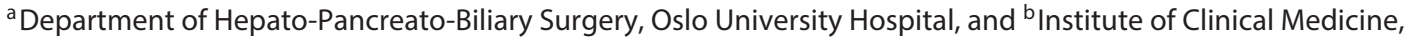 \\ University of Oslo, Oslo, Norway; ' Unit of Gastroenterology, Department of Medicine, Sahlgrenska University \\ Hospital, Gothenburg, Sweden; 'Digestive and Liver Disease Unit, II Medical School, University 'La Sapienza', \\ S. Andrea Hospital, Rome, and ' Division of Epidemiology and Biostatistics, European Institute of Oncology,

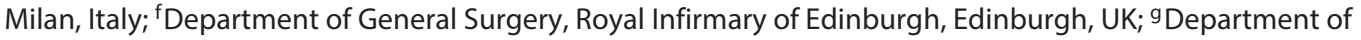 \\ Gastroenterology, University Medical Center Ljubljana, Ljubljana, Slovenia
}

\section{Key Words}

Pancreatic neuroendocrine tumor - Neuroendocrine tumor - Sporadic pancreatic neuroendocrine tumor . Epidemiology $\cdot$ Meta-analysis · Risk factor

\footnotetext{
Abstract

Background and Aims: Risk factors for pancreatic neuroendocrine tumors (PNETs) are not well understood. The aim of this systematic review was to assess if diabetes mellitus, smoking, alcohol use, and family history of cancer are risk factors for PNETs. Methods: MEDLINE and abstracts from the European and North American Neuroendocrine Tumor Societies (ENETS and NANETS) were searched for studies published until October 2013. Eligible studies were selected according to the Preferred Reporting Items for Systematic Reviews and Meta-Analyses (PRISMA) statement. Results: Five studies evaluating 4 individual populations were included (study accrual period 2000-2011) into the meta-analysis, in-
}

volving 827 cases (range 160-309 per study) and 2,407 controls (range 233-924 per study). All studies had a case-control design and described regional series. The pooled adjusted odds ratio was $2.74\left(95 \% \mathrm{Cl}: 1.63-4.62 ; \mathrm{p}<0.01 ; \mathrm{I}^{2}=60.4 \%\right)$ for history of diabetes, $1.21\left(95 \% \mathrm{Cl}: 0.92-1.58 ; \mathrm{p}=0.18 ; \mathrm{I}^{2}=\right.$ 45.8\%) for ever smoking, 1.37 (95\% Cl: 0.99-1.91; $p=0.06$; $\left.\mathrm{I}^{2}=0.0 \%\right)$ for heavy smoking, 1.09 (95\% Cl: 0.64-1.85; $\mathrm{p}=$ $\left.0.75 ; \mathrm{I}^{2}=85.2 \%\right)$ for ever alcohol use, 2.72 (95\% Cl: 1.25-5.91; $\left.\mathrm{p}=0.01 ; \mathrm{I}^{2}=57.8 \%\right)$ for heavy alcohol use, and $2.16(95 \% \mathrm{Cl}$ : $\left.1.64-2.85 ; \mathrm{p}<0.01 ; 1^{2}=0.0 \%\right)$ for first-degree family history of cancer. Conclusions: Diabetes mellitus and first-degree family history of cancer are associated with an increased risk of sporadic PNET. There was also a trend for diagnosis of sporadic PNET associated with heavy smoking. Alcohol use may be a risk factor for PNET, but there was considerable heterogeneity in the meta-analysis. These results suggest the need for a larger, homogeneous, international study for the clarification of risk factors for the occurrence of PNET.

\section{KARGER 125}

(c) 2015 S. Karger AG, Base

0028-3835/15/1012-0133\$39.50/0 


\section{Introduction}

Gastroenteropancreatic neuroendocrine tumors (NETs) make up over half of all NETs and are their most common subgroup. Approximately $4-7 \%$ of gastroenteropancreatic NETs originate in the pancreas, and these are referred to as pancreatic NETs (PNETs) [1]. Whilst there is evidence to suggest the possibility of an increasing incidence, PNETs currently arise in approximately 0.3 per 100,000 people in Western society [2,3]. The relatively indolent clinical course of PNETs, relative to that of the much more common pancreatic ductal adenocarcinoma (PDAC), explains why the overall prevalence of PNETs accounts for as many as $10 \%$ of pancreatic neoplasms despite the low incidence.

On diagnosis, a PNET is often described as either sporadic or hereditary, with the latter being less common. The pathogenesis of sporadic PNET and the contributing factors that increase the risk within the population are not well defined. PDAC oncogenesis has received more investigation in this regard, and there is reasonable evidence that diabetes [4], alcohol consumption [5], smoking [6], and family history of cancer [7] each independently infer an increased risk of PDAC. Environmental and nonmodifiable risk factors for sporadic PNET are less well characterized, since there has been little research in this area. Based on the limited number of studies available, it has been suggested that chronic pancreatitis [8], high alcohol intake [8], diabetes mellitus $[8,9]$, underweight [9], origin from rural areas [10], family history of PNET [10], family history of any cancer $[8,10]$, and family history of esophageal cancer [11] or PDAC [8] are to be considered risk factors for PNET.

Given that the incidence of PNETs may be increasing [3], there is an emerging need for a clarification and further investigation of factors which might increase the risk of the development of PNETs within the population. Accordingly, we report a systematic review and meta-analysis to evaluate the association of diabetes mellitus, smoking, alcohol use, and first-degree family history of cancer with the risk of developing PNET.

\section{Materials and Methods}

\section{Literature Search Strategy}

A computerized literature search of MEDLINE and the Cochrane Database of Systematic Reviews for a prior systematic review on risk factors for the occurrence of PNETs revealed that there was no previous publication on this topic. In our search for original studies, we performed a MEDLINE search (until October 26, 2013) as well as a hand search of conference abstracts presented at the European Neuroendocrine Tumor Society (ENETS) meetings from 2009 to 2013 and the North American Neuroendocrine Tumor Society (NANETS) meetings from 2008 to 2012. Specific search terms were defined and are detailed in online supplementary Appendix S1 (see www.karger.com/doi/10.1159/375164 for all online suppl. material). The methodology was developed from the Preferred Reporting Items for Systematic Reviews and MetaAnalyses (PRISMA) statement [12].

The titles of all identified articles were screened to ascertain their relevance. The abstracts and/or full texts of selected, potentially relevant papers were further evaluated. Additional articles were identified by hand-searching reference lists of all the articles retrieved to identify potentially relevant studies.

\section{Inclusion and Exclusion Criteria}

We included studies related to our research question if they were either cohort or case-control studies with available data for a quantitative synthesis, meaning that they included a minimum of information necessary to estimate the relative risk (RR) or odds ratio (OR) for occurrence of PNETs associated with any of the exposures investigated. Thus, included studies had to: (1) evaluate exposure to smoking, alcohol use, personal history of diabetes, or family history of cancer in a cohort or population that included internal controls; (2) evaluate the occurrence or diagnosis of PNET, and (3) report the RR or OR with $95 \%$ CI or original raw data sufficient to evaluate the hypothesized effect. No language filters were applied. In the event of duplicate publications, the most recent or more complete publication was used.

Four independent reviewers (R.V., D.S., E.K., and S.P.H.) completed a study identification and selection search in MEDLINE, and disagreements were discussed with a another reviewer (G.C.). Similarly, another two reviewers (P.H. and A.H.) selected suitable conference proceeding abstracts from the ENETS and NANETS. Excluded studies and reasons for exclusion were recorded.

\section{Outcome and Exposure Measures}

The outcome measured was the diagnosis of PNET. The exposures assessed were diabetes mellitus, ever smoking, heavy smoking, ever alcohol use, heavy alcohol use, and first-degree family history of any cancer. The definitions for such exposures and family history for each individual study are reported in online supplementary table 1 .

\section{Data Extraction}

From the studies that met the eligibility criteria, the following data were collected: (1) study - year of publication, nationality, study accrual period, study design, and type of interview; (2) cases - definition (i.e. clinical charts, histological diagnosis, or other means), number, hormonal activity (functioning, nonfunctioning), hereditary or sporadic disease, gender, and age; (3) controls - number and source of controls and matching design; (4) type of exposure - definition, dosage, and length of exposure, and (5) type of outcome measures. We developed a summary table of the relevant studies, listing the population characteristics, exposures, and outcome (table 1). The quality of each study was assessed according to a dedicated quality appraisal tool (Newcastle-Ottawa Scale) including 8 items (total score range 0-9) specifically developed for case-control studies [13]. 
Table 1. Characteristics of the studies included in the meta-analysis

\begin{tabular}{|c|c|c|c|c|c|c|c|c|c|c|c|c|}
\hline Study & Year & Country & $\begin{array}{l}\text { Study accrual } \\
\text { period }\end{array}$ & $\begin{array}{l}\text { Setting } \\
\text { and de- } \\
\text { sign }\end{array}$ & $\begin{array}{l}\text { Number } \\
\text { of cases }\end{array}$ & $\mathrm{F} / \mathrm{NF}$ & $\begin{array}{l}\text { MEN-1 } \\
\text { patients, } \\
\text { n }\end{array}$ & $\begin{array}{l}\text { Male } \\
\text { sex, } \\
\%\end{array}$ & $\begin{array}{l}\text { Mean age, } \\
\text { years }\end{array}$ & $\begin{array}{l}\text { Number } \\
\text { of con- } \\
\text { trols }\end{array}$ & Investigated exposures & $\begin{array}{l}\text { Outcome } \\
\text { measures }\end{array}$ \\
\hline $\begin{array}{l}\text { Capurso et al. } \\
{[8]}\end{array}$ & 2009 & Italy & $2006-2008$ & CCS & 162 & $31 / 131$ & 0 & 49 & 53.0 & 648 & $\begin{array}{l}\text { diabetes, ever/heavy } \\
\text { smoking, ever/heavy } \\
\text { alcohol use, family history } \\
\text { of cancer }\end{array}$ & OR \\
\hline $\begin{array}{l}\text { Hassan et al. } \\
{[9]^{\mathrm{a}}}\end{array}$ & 2008 & USA & $2000-2006$ & CCS & 160 & NA & 11 & 60 & 56.8 & 924 & $\begin{array}{l}\text { diabetes, ever/heavy } \\
\text { smoking, ever/heavy } \\
\text { alcohol use }\end{array}$ & OR \\
\hline Zhan et al. [10] & 2013 & China & $2000-2010$ & CCS & 196 & $196 / 0$ & 12 & 45 & 44.9 & 233 & $\begin{array}{l}\text { ever/heavy smoking, ever/ } \\
\text { heavy alcohol use, family } \\
\text { history of cancer }\end{array}$ & OR \\
\hline $\begin{array}{l}\text { Hassan et al. } \\
{[11]^{\mathrm{a}}}\end{array}$ & 2008 & USA & $2000-2006$ & CCS & 160 & NA & 11 & 60 & 56.8 & 924 & $\begin{array}{l}\text { ever smoking, ever alcohol } \\
\text { use, family history of } \\
\text { cancer }\end{array}$ & OR \\
\hline $\begin{array}{l}\text { Halfdanarson } \\
\text { et al. }[17]^{\mathrm{b}}\end{array}$ & 2012 & USA & $2000-2011$ & CCS & 309 & NA & NA & 52 & 56.6 & 602 & $\begin{array}{l}\text { diabetes, ever smoking, } \\
\text { ever alcohol use }\end{array}$ & percentages \\
\hline
\end{tabular}

$\mathrm{CCS}=$ Case-control study; $\mathrm{F}=$ functioning; $\mathrm{MEN}-1=$ multiple endocrine neoplasia type 1 ; NF = nonfunctioning; NA = not available. ${ }^{\text {a }}$ The 2 studies by Hassan et al. $[9,11]$ report different risk factors for the same study population. ${ }^{\mathrm{b}}$ This study was only published in abstract form.

\section{Statistical Analysis}

The agreement between reviewers for the assessment of eligibility was calculated. A meta-analysis of all eligible studies identified was planned using the software package Comprehensive $\mathrm{Me}$ ta-Analysis (Biostat, Englewood, N.J., USA) with the following methods: calculation of the pooled estimates (OR and 95\% CI) using the DerSimonian-Laird method as well as a random-effects model in the presence of heterogeneity or a fixed model in the presence of trivial heterogeneity. The quantity of heterogeneity was assessed by means of the $\mathrm{I}^{2}$ value [14-16]. We considered an $\mathrm{I}^{2}$ value of $\leq 25 \%$ as trivial heterogeneity and an $\mathrm{I}^{2}$ value of $\geq 75 \%$ as important heterogeneity. A p value $<0.05$ was accepted as statistically significant.

\section{Results}

\section{Search Result and Study Selection}

A total of 5,912 references were identified by the MEDLINE search (fig. 1). After the evaluation of 1,025 conference abstracts, 2 relevant studies were identified $[17,18]$. Together, the 5,914 records were screened, and 5,749 studies were excluded as they were unrelated to the study topic. Thus, the remaining 165 studies were examined in detail, leaving 6 as potentially appropriate for inclusion into the meta-analysis $[8-11,17,18]$. However, 2 of these studies $[17,18]$ reported on a duplicate cohort, and, accordingly, the smaller study [18] was excluded. Two studies reported different risk factors for the same study population; thus, both of them were included separately into the meta-analysis $[9,11]$. Therefore, 5 studies, which investigated 4 independent study populations, remained for qualitative analysis and quantitative synthesis (table 1) [8-11, 17]. There was absolute agreement amongst the reviewers for the assessment of eligibility and selection of studies.

\section{Study Characteristics}

Table 1 shows the descriptive characteristics of the 5 studies identified from the systematic search. One study was conducted on cases diagnosed with either a functioning or a nonfunctioning PNET [8] and 1 study [10] included cases with functioning PNET only, whereas 3 studies did not describe the biological behavior of the tumors $[9,11,17]$. All reported on the history of smoking and alcohol use, whereas 3 of them reported on the history of diabetes $[8,9,17]$ and the first-degree family history of cancer $[8,10,11]$. Patients with hereditary PNET were specifically excluded in only 1 of these studies $[9$, 17].

Data collection was performed prospectively with standardized questionnaires in 1 study [8], retrospectively with standardized questionnaires in 3 studies $[9,11$, 17], and with a combination of medical records and telephone interviews in the remaining study [10]. 
Fig. 1. PRISMA diagram showing the selection of studies for review.

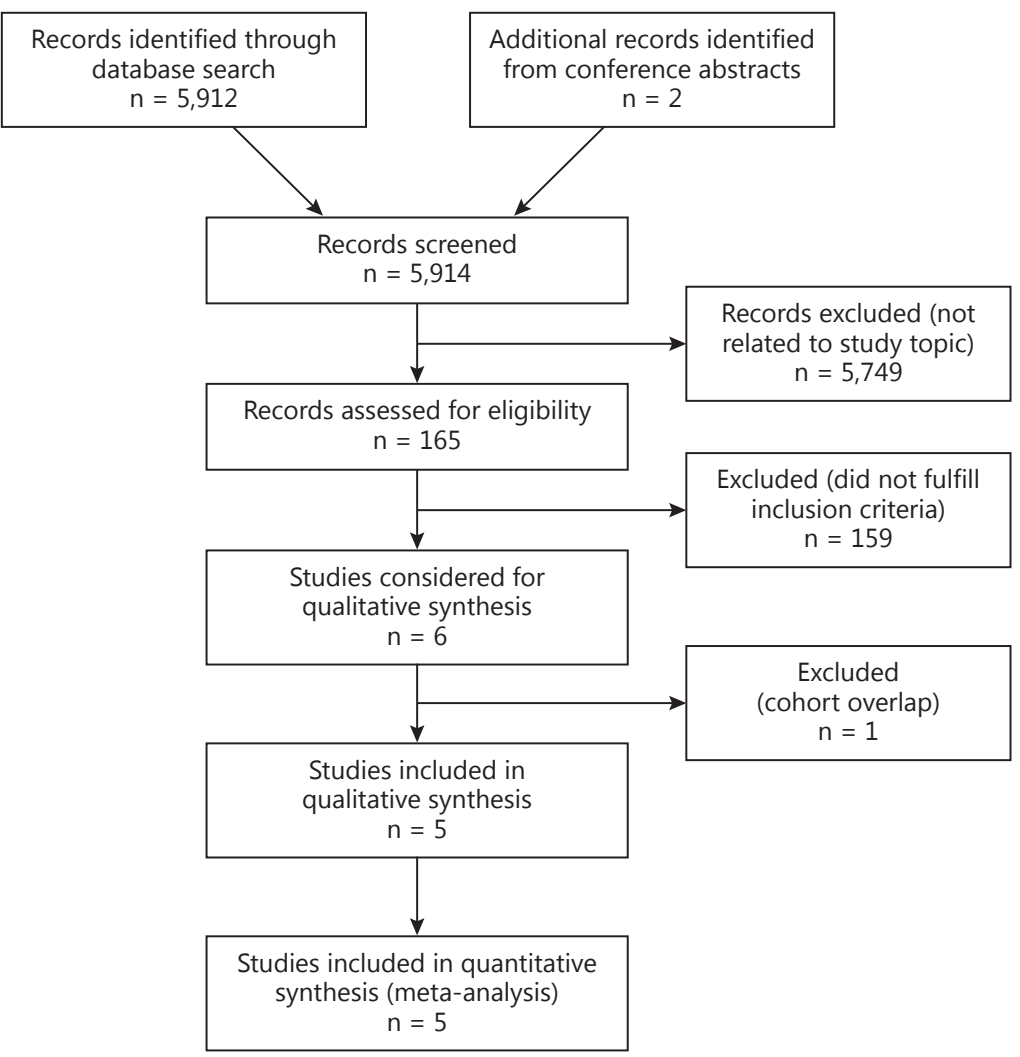

Controls were defined as patients who had undergone operations at a department of general surgery during the same period, with specific exclusion criteria, in 1 study [10]; as patients visiting a radiology department during the same period, with specific exclusion criteria, in 1 study [9]; as primary care patients without any further description available in 1 study [17], and as patients visiting a gastrointestinal outpatient clinic during the same period, with specific exclusion criteria, in 1 study [8]. The inclusion and exclusion criteria for cases and controls are summarized in table 2 . The quality of each study was assessed in the 4 full-text papers [8-11], since not enough data were obtained in the abstract analyzed [17]. As 2 of the studies were conducted on the same study population $[9,11]$, the quality data concerned 3 of the studies. The quality score was 6/9 in 1 study [8] and 4/9 in the other 2 $[9,10]$.

The 5 studies that were included in the meta-analysis reported on 4 regional study cohorts with 827 cases (range 160-309 per study) and 2,407 controls (range 233-924 per study) and accrual periods between 2000 and 2011. Table 1 shows the descriptive characteristics of the 5 studies included.

\section{Risk of Sporadic PNET: History of Diabetes Mellitus}

Figure 2 shows the OR for the individual studies reporting on history of diabetes. The pooled estimated OR for the 3 study populations $[8,9]$ showing diabetes as an exposure was 2.74 (95\% CI: $1.63-4.62 ; \mathrm{p}<0.01$ ), indicating diabetes as a strong risk factor for the development of PNET. For only 1 [9] of the 3 studies was the OR employed from a multivariate analysis. The $\mathrm{I}^{2}$ value was $60.4 \%$.

\section{Risk of Sporadic PNET: History of Smoking}

Figure 3 shows the OR for the individual studies reporting on history of ever smoking. The pooled estimated OR for the 4 study populations [8-10] showing history of ever smoking as an exposure was 1.21 (95\% CI: 0.92-1.58; $\mathrm{p}=0.18$ ), indicating that ever smoking is not a significant 


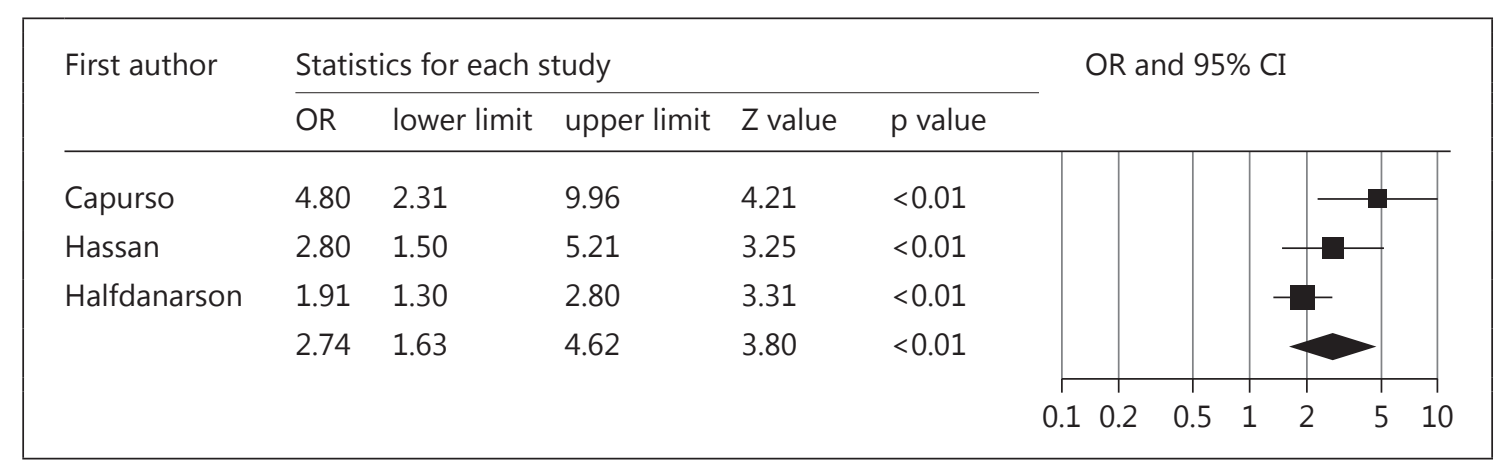

Fig. 2. Forest plot, summary OR, and $95 \%$ CIs for history of diabetes and risk of sporadic PNET. OR $<1$ : risk of sporadic PNET reduced. OR >1: risk of sporadic PNET increased. $\mathrm{I}^{2}=60.4 \%$.

Table 2. Inclusion and exclusion criteria for cases and controls in the different studies

\begin{tabular}{|c|c|c|}
\hline & Inclusion criteria & Exclusion criteria \\
\hline \multicolumn{3}{|l|}{ Cases } \\
\hline Capurso et al. [8] & Confirmed histological PNET & Genetic syndromes associated with PNET \\
\hline Hassan et al. $[9,11]$ & $\begin{array}{l}\text { Confirmed histological PNET; } \\
\text { US residents }\end{array}$ & Not specified \\
\hline Zhan et al. [10] & Confirmed histological insulinoma & $\begin{array}{l}\text { Other PNET such as gastrinoma, } \\
\text { glucagonoma and nonfunctioning PNET }\end{array}$ \\
\hline Halfdanarson et al. [17] & NA & NA \\
\hline \multicolumn{3}{|l|}{ Controls } \\
\hline Capurso et al. [8] & $\begin{array}{l}\text { Outpatients for evaluation of } \\
\text { different gastrointestinal disorders }\end{array}$ & $\begin{array}{l}\text { Current or previous diagnosis of cancer or } \\
\text { chronic disorders; genetic relation with a } \\
\text { study patient; specific referral for evaluation } \\
\text { of a possible cancer familial syndrome }\end{array}$ \\
\hline Hassan et al. $[9,11]$ & $\begin{array}{l}\text { Genetically unrelated and healthy } \\
\text { family members who accompanied } \\
\text { cancer patients who had cancers } \\
\text { other than gastrointestinal, lung, or } \\
\text { head and neck cancer; US residents }\end{array}$ & Past history of cancer \\
\hline Zhan et al. [10] & $\begin{array}{l}\text { Patients who underwent operations } \\
\text { at the same department during the } \\
\text { same period }\end{array}$ & $\begin{array}{l}\text { Benign or malignant tumor; autoimmune or } \\
\text { chronic diseases; genetic relation with } \\
\text { insulinoma; specific referral for evaluation of } \\
\text { a possible cancer familial syndrome }\end{array}$ \\
\hline Halfdanarson et al. [17] & NA & NA \\
\hline
\end{tabular}

risk factor for the development of sporadic PNET. The $I^{2}$ value was $45.8 \%$.

Figure 4 shows the OR for the individual studies reporting on history of heavy smoking. The pooled estimated OR of the 3 study populations [8-10] showing history of heavy smoking as an exposure was 1.37 (95\% CI:
0.99-1.91; $\mathrm{p}=0.06$ ), indicating heavy smoking as a borderline significant risk factor for the development of sporadic PNET. There was no heterogeneity for this analysis (the $\mathrm{I}^{2}$ value was $0 \%$ ). As for the two analyses investigating the role of smoking, only 1 of the studies [9] reported an OR as calculated from a multivariate analysis. 


\begin{tabular}{|c|c|c|c|c|c|c|c|c|c|c|c|}
\hline \multirow{3}{*}{$\begin{array}{l}\text { First author } \\
\text { Capurso }\end{array}$} & \multicolumn{5}{|c|}{ Statistics for each study } & \multirow{2}{*}{\multicolumn{6}{|c|}{ OR and $95 \% \mathrm{CI}$}} \\
\hline & OR & lower limit & upper limit & $Z$ value & $p$ value & & & & & & \\
\hline & 1.40 & 0.94 & 2.09 & 1.65 & 0.10 & & & & & & \\
\hline Hassan & 1.20 & 0.73 & 1.98 & 0.72 & 0.47 & & & - & & & \\
\hline Zhan & 1.60 & 1.01 & 2.54 & 2.00 & 0.05 & & & $\mapsto$ & & & \\
\hline \multirow[t]{3}{*}{ Halfdanarson } & 0.91 & 0.69 & 1.21 & -0.65 & 0.52 & & & - & & & \\
\hline & 1.21 & 0.92 & 1.58 & 1.35 & 0.18 & & & & & & \\
\hline & & & & & & 0.10 .2 & 0.5 & 1 & 2 & 5 & 10 \\
\hline
\end{tabular}

Fig. 3. Forest plot, summary OR, and 95\% CIs for history of ever smoking and risk of PNET. OR < 1: risk of sporadic PNET reduced. OR >1: risk of sporadic PNET increased. $\mathrm{I}^{2}=45.8 \%$.

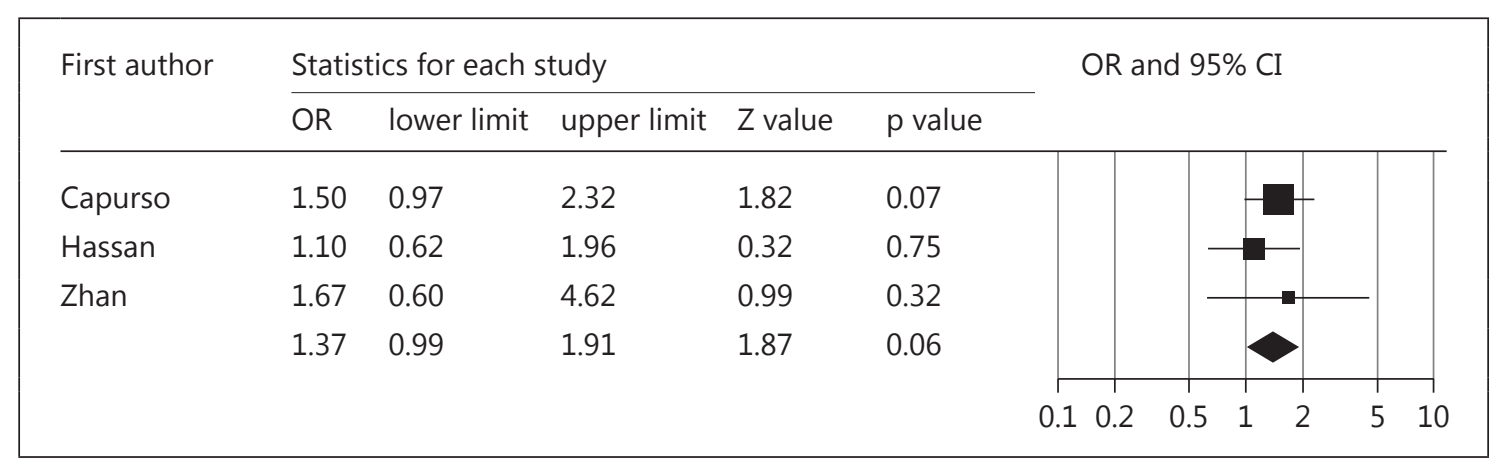

Fig. 4. Forest plot, summary OR, and $95 \%$ CIs for history of heavy smoking and risk of PNET. OR <1: risk of sporadic PNET reduced. OR >1: risk of sporadic PNET increased. $\mathrm{I}^{2}=0.0 \%$.

\begin{tabular}{|c|c|c|c|c|c|c|c|c|c|c|}
\hline \multirow{3}{*}{$\begin{array}{l}\text { First author } \\
\text { Capurso }\end{array}$} & \multicolumn{5}{|c|}{ Statistics for each study } & \multicolumn{5}{|c|}{ OR and $95 \% \mathrm{CI}$} \\
\hline & \multirow{2}{*}{$\frac{\mathrm{OR}}{1.50}$} & \multirow{2}{*}{$\begin{array}{l}\text { lower limit } \\
1.01\end{array}$} & \multirow{2}{*}{$\begin{array}{l}\text { upper limit } \\
2.22\end{array}$} & \multirow{2}{*}{$\begin{array}{l}Z \text { value } \\
2.02\end{array}$} & \multicolumn{6}{|l|}{$p$ value } \\
\hline & & & & & 0.04 & & & & & \\
\hline Hassan & 1.20 & 0.73 & 1.98 & 0.72 & 0.47 & & & & & \\
\hline Zhan & 1.45 & 0.88 & 2.38 & 1.47 & 0.14 & & 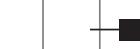 & & & \\
\hline \multirow[t]{3}{*}{ Halfdanarson } & 0.58 & 0.44 & 0.77 & -3.75 & $<0.01$ & & + & & & \\
\hline & 1.09 & 0.64 & 1.85 & 0.31 & 0.75 & & & & & \\
\hline & & & & & & $\begin{array}{ll}1 & 0.2\end{array}$ & 0.51 & 2 & 5 & 10 \\
\hline
\end{tabular}

Fig. 5. Forest plot, summary OR, and $95 \%$ CIs for history of ever alcohol use and risk of PNET. OR <1: risk of sporadic PNET reduced. OR $>1$ : risk of sporadic PNET increased. $\mathrm{I}^{2}=85.2 \%$. 


\begin{tabular}{|c|c|c|c|c|c|c|c|c|c|c|c|}
\hline \multirow{3}{*}{$\begin{array}{l}\text { First author } \\
\text { Capurso }\end{array}$} & \multicolumn{5}{|c|}{ Statistics for each study } & \multirow{2}{*}{\multicolumn{6}{|c|}{ OR and $95 \% \mathrm{CI}$}} \\
\hline & OR & lower limit & upper limit & $Z$ value & $p$ value & & & & & & \\
\hline & 4.80 & 2.61 & 8.81 & 5.06 & $<0.01$ & & & & & & \\
\hline Hassan & 1.00 & 0.22 & 4.51 & 0.00 & 1.00 & & & & & & \\
\hline \multirow[t]{3}{*}{ Zhan } & 2.29 & 1.07 & 4.91 & 2.13 & 0.03 & & & & & & \\
\hline & 2.72 & 1.25 & 5.91 & 2.52 & 0.01 & & & & & & \\
\hline & & & & & & 0.10 .2 & 0.5 & 1 & 2 & 5 & 10 \\
\hline
\end{tabular}

Fig. 6. Forest plot, summary OR, and 95\% CIs for history of heavy alcohol use and risk of PNET. OR <1: risk of sporadic PNET reduced. OR $>1$ : risk of sporadic PNET increased. $\mathrm{I}^{2}=57.8 \%$.

\begin{tabular}{|c|c|c|c|c|c|c|c|c|c|c|c|}
\hline \multirow{3}{*}{$\begin{array}{l}\text { First author } \\
\text { Capurso }\end{array}$} & \multicolumn{5}{|c|}{ Statistics for each study } & \multirow{2}{*}{\multicolumn{6}{|c|}{ OR and $95 \% \mathrm{CI}$}} \\
\hline & OR & lower limit & upper limit & $Z$ value & $p$ value & & & & & & \\
\hline & 2.30 & 1.60 & 3.30 & 4.51 & $<0.01$ & & & & & & \\
\hline Hassan & 1.80 & 1.07 & 3.02 & 2.22 & 0.03 & & & & & & \\
\hline \multirow[t]{3}{*}{ Zhan } & 2.42 & 1.14 & 5.15 & 2.29 & 0.02 & & & & & & \\
\hline & 2.16 & 1.64 & 2.85 & 5.47 & $<0.01$ & & & & & & \\
\hline & & & & & & 0.10 .2 & 0.5 & 1 & 2 & 5 & 10 \\
\hline
\end{tabular}

Fig. 7. Forest plot, summary OR, and $95 \%$ CIs for first-degree family history of any cancer and risk of PNET. OR $<1$ : risk of sporadic PNET reduced. OR $>1$ : risk of sporadic PNET increased. $\mathrm{I}^{2}=0.0 \%$.

Risk of Sporadic PNET: History of Alcohol Use

Figure 5 shows the OR for the individual studies reporting on history of ever alcohol use. The pooled estimated OR of the 4 study populations [8-10] showing ever alcohol use as a risk factor was 1.09 (95\% CI: 0.64$1.85 ; \mathrm{p}=0.75$ ). For only 1 [9] of the 3 studies was the OR employed from a multivariate analysis. The $\mathrm{I}^{2}$ value was $85.2 \%$, suggesting strong heterogeneity between the studies analyzed. However, only in 1 study [17] was alcohol use less common among cases than controls (54 as compared with $67 \%$ among the controls). Thus, we performed a sensitivity analysis excluding this study. The pooled estimated OR for the 3 other study populations [8-10] was 1.39 (95\% CI: $1.07-1.81 ; \mathrm{p}=0.01)$, without heterogeneity (the $\mathrm{I}^{2}$ value was $0 \%$ ), which indicates alcohol use as a moderate risk factor for the development of PNET.
Figure 6 shows the OR for the individual studies reporting on history of heavy alcohol use. The pooled estimated OR for the 3 study populations [8-10] showing heavy alcohol use as a risk factor was 2.72 (95\% CI: 1.255.91; $\mathrm{p}=0.01$ ), indicating heavy alcohol use as a strong risk factor for the development of PNET. For 2 of the 3 studies included in this analysis $[8,9]$, the OR were from a multivariate analysis. The $\mathrm{I}^{2}$ value was $57.8 \%$. One study did not report data about heavy alcohol use and was therefore not included in this latter analysis [17].

\section{Risk of Sporadic PNET: First-Degree Family History of Any Cancer}

Figure 7 shows the OR for the individual studies reporting on first-degree family history of any cancer. The pooled estimated OR for the 3 study populations [8-10] showing first-degree family history of any cancer as a risk 
factor was 2.16 (95\% CI: 1.64-2.85; p < 0.01), indicating family history of any cancer as a strong risk factor for the development of PNET. For 2 of the 3 studies included in this analysis $[8,9]$, the OR were from a multivariate analysis. The $\mathrm{I}^{2}$ value was $0 \%$.

\section{Discussion}

The present study was aimed at systematically reviewing the studies that explored the relation of diabetes, smoking, alcohol use, and family history of cancer to the occurrence of PNET. The resulting pooled meta-analysis included 4 study populations with data from 827 cases and 2,407 controls. It demonstrates that a history of diabetes and a first-degree family history of cancer are associated with an increased risk of developing PNET, while the role of alcohol use and smoking is less clear. Considerable heterogeneity was identified in the analysis, which was most apparent with regard to the risk associated with smoking and alcohol use.

In the present analysis, diabetes was identified as the strongest risk factor for developing PNET, with an OR as high as 2.74 (fig. 2). In all 3 cohorts that were investigated concerning its role, diabetes was found to be associated with an increased risk $[8,9,17]$. However, only 1 of the 3 studies [8] also considered the role of recent-onset diabetes, for which the association appeared stronger. Whether diabetes is truly a risk factor for the occurrence of PNETs, or whether this association is a secondary effect related to the pancreatic tumor, is unclear, and further research would be required to clarify this issue.

A family history of cancer was also associated with a twice increased risk of PNET; this result was consistent among all the studies included, without heterogeneity (fig. 7). As regards specific cancer sites, the studies screened showed an increased risk for subjects with a family history of pancreatic adenocarcinoma and hepatobiliary neoplasms [8], esophageal cancer [11], or with a family history of sarcoma and ovary, stomach, and gallbladder cancers [17]. Family history of PNET was a significant risk factor in 2 studies [10, 17]. However, those 2 studies also included patients with hereditary PNET [i.e. multiple endocrine neoplasia type 1 (MEN-1)]. Although the percentage of MEN-1 patients was low - that is, around $6 \%$ in these 2 cohorts $[10,11]$ and not specified in another [17], since the reported ORs are based on the entire populations - it remains unclear as to what extent MEN-1 has influenced the pooled ORs of the present meta-analysis. At any rate, the increased risk of developing
PNET in individuals with a first-degree family history of other cancers might be related to unknown genetic factors, or to shared environmental factors, and this finding reflects current knowledge with regard to other tumor types $[19,20]$.

The role of smoking and alcohol use seemed less clear in the present analysis. Ever smoking did not appear to be associated with an increased risk of PNET (fig. 3), while heavy smoking was associated with a moderate risk, but this relation did not reach statistical significance (fig. 4).

Ever alcohol use did not seem to be a significant risk factor in our meta-analysis (fig. 5), while heavy alcohol use was a significant risk factor (fig. 6). In 1 of the studies, which was conducted on a population of 309 cases and 602 controls, alcohol use was more frequent amongst controls, suggesting a protective benefit with regard to the development of PNETs [17]. As that study was not subject to a full paper review (being published as a conference proceeding only), we performed a sensitivity analysis after having omitted its results, and alcohol use was accordingly identified as a positive risk factor. At any rate, there were discrepancies in terms of the ORs for smoking and drinking alcohol between the studies conducted in the USA $[9,11]$ and the 2 other studies included in the meta-analysis $[8,10]$. This seems most likely due to the higher proportion of smokers and alcohol drinkers in the control populations of the US studies, and this appears to be even more relevant in the study by Halfdanarson et al. [17]. Furthermore, as all the studies included have a casecontrol design, their retrospective nature might have caused biases. Notably, in only 1 of the studies included for the analysis is it specified that the patients were asked about whether risk factors had been present 12 months before the diagnosis or presentation of symptoms [8]. It is possible that in other studies, the patients might have changed their habits (i.e. quitting smoking or drinking alcohol) at the time of the first symptoms or diagnosis, and thus the role of such environmental factors might have been undervalued, while this was not the case with the controls. Another possible explanation for the reported heterogeneity might be linked to the heterogeneous ethnicities in the US studies, since the studies from Italy and China only included Caucasian and Asian patients, respectively $[8,10]$. Furthermore, as alcohol drinking and smoking might act as mutual potential confounders, we employed data from multivariate analyses from the identified papers when available to minimize biases. Interestingly, the role of smoking and alcohol drinking was also found to be unclear in an uncontrolled series that did not meet the criteria for inclusion into our analysis [21]. 
Large, well-conducted studies need to better investigate the relation between such environmental risk factors and the occurrence of PNETs.

The present study has a number of limitations. First, since we have been able to include only a limited number of studies, which were conducted on relatively small series, the evidence obtained with the present results might be inadequate, and further studies on this topic seem necessary. As for any analysis of this kind, the heterogeneity observed is also related to possible differences in patient and control groups between the individual studies (table 2). One study only included patients with insulinoma [10] and another included both functioning and nonfunctioning PNETs, with a majority of nonfunctioning tumors $(81 \%)$ [8], while tumor characteristics were not specified in 2 further studies $[9,11]$. The definition of the control groups also varied between studies. We employed two strategies to deal with this heterogeneity: we used a random-effects model for all analyses, and we performed sensitivity analyses. Using a random-effects model, however, might produce wider CIs. Moreover, most tests for heterogeneity tend to underestimate the magnitude of heterogeneity, and, given the paucity of studies, the results should therefore be interpreted with some caution and mainly be employed to design further investigations. Finally, we only focused our attention on risk factors for which there was a biological plausibility, and for which we were aware of available data from the literature. Interestingly, all these factors are also related to the risk of de- veloping pancreatic adenocarcinoma, thus suggesting that these two neoplasms might share some risk factors.

In conclusion, our systematic review and meta-analysis has identified diabetes mellitus and first-degree family history of cancer as being associated with an increased risk of sporadic PNET. There was a trend for an association between the occurrence of PNET and heavy smoking, but this did not reach statistical significance. Alcohol use may be a risk factor for PNET, but there was considerable heterogeneity in the meta-analysis. As the studies evaluated in this meta-analysis differ in terms of their design and population definition, and are limited in terms of the number of patients and their quality, we perceive the need for a large multicenter study using a homogeneous design as well as rigorous definitions of the study population and control exposures. Such an investigation might help us to draw definitive conclusions, especially with regard to smoking and alcohol use, and to assess associations with other potential risk factors for sporadic PNET that we have not been able to include in the present analysis.

\section{Acknowledgements}

This study was conducted through Pancreas 2000, which is a European educational and scientific pancreatology program initiated by Karolinska Institutet in Stockholm, Sweden, and the European Pancreatic Club.

\section{References}

1 Hauso O, Gustafsson BI, Kidd M, Waldum HL, Drozdov I, Chan AK, Modlin IM: Neuroendocrine tumor epidemiology: contrasting Norway and North America. Cancer 2008; 113:2655-2664.

-2 Yao JC, Hassan M, Phan A, Dagohoy C, Leary C, Mares JE, Abdalla EK, Fleming JB, Vauthey JN, Rashid A, Evans DB: One hundred years after 'carcinoid': epidemiology of and prognostic factors for neuroendocrine tumors in 35,825 cases in the United States. J Clin Oncol 2008;26:3063-3072.

- 3 Fitzgerald TL, Hickner ZJ, Schmitz M, Kort EJ: Changing incidence of pancreatic neoplasms: a 16-year review of statewide tumor registry. Pancreas 2008;37:134-138.

4 Ben Q, Xu M, Ning X, Liu J, Hong S, Huang W, Zhang H, Li Z: Diabetes mellitus and risk of pancreatic cancer: a meta-analysis of cohort studies. Eur J Cancer 2011;47:19281937.
5 Lucenteforte E, La Vecchia C, Silverman D, Petersen GM, Bracci PM, Ji BT, Bosetti C, Li $\mathrm{D}$, Gallinger S, Miller AB, Bueno-de-Mesquita HB, Talamini R, Polesel J, Ghadirian P, Baghurst PA, Zatonski W, Fontham E, Bamlet WR, Holly EA, Gao YT, Negri E, Hassan M, Cotterchio M, Su J, Maisonneuve P, Boffetta P, Duell EJ: Alcohol consumption and pancreatic cancer: a pooled analysis in the International Pancreatic Cancer Case-Control Consortium (PanC4). Ann Oncol 2012;23: 374-382.

-6 Bosetti C, Lucenteforte E, Silverman DT, et al: Cigarette smoking and pancreatic cancer: an analysis from the International Pancreatic Cancer Case-Control Consortium (Panc4). Ann Oncol 2012;23:1880-1888.

7 Jacobs EJ, Chanock SJ, Fuchs CS, et al: Family history of cancer and risk of pancreatic cancer: a pooled analysis from the Pancreatic Cancer Cohort Consortium (PanScan). Int J Cancer 2010;127:1421-1428.
8 Capurso G, Falconi M, Panzuto F, Rinzivillo M, Boninsegna L, Bettini R, Corleto V, Borgia P, Pederzoli P, Scarpa A, Delle Fave G: Risk factors for sporadic pancreatic endocrine tumors: a case-control study of prospectively evaluated patients. Am J Gastroenterol 2009; 104:3034-3041.

\9 Hassan MM, Phan A, Li D, Dagohoy CG Leary C, Yao JC: Risk factors associated with neuroendocrine tumors: a US-based casecontrol study. Int J Cancer 2008;123:867-873.

10 Zhan HX, Cong L, Zhao YP, Zhang TP, Chen G: Risk factors for the occurrence of insulinoma: a case-control study. Hepatobiliary Pancreat Dis Int 2013;12:324-328.

11 Hassan MM, Phan A, Li D, Dagohoy CG, Leary C, Yao JC: Family history of cancer and associated risk of developing neuroendocrine tumors: a case-control study. Cancer Epidemiol Biomarkers Prev 2008;17:959-965. 
12 Moher D, Liberati A, Tetzlaff J, Altman DG: Preferred reporting items for systematic reviews and meta-analyses: the PRISMA statement. PLoS Med 2009;6:e1000097.

13 Wells GA, Shea B, O'Connell D, Peterson J, Welch V, Losos M, Tugwell P: The NewcastleOttawa Scale (NOS) for assessing the quality of nonrandomised studies in meta-analyses. http://www.ohri.ca/programs/clinical_ epidemiology/oxford.asp.

14 DerSimonian R, Laird N: Meta-analysis in clinical trials. Control Clin Trials 1986;7:177188.

15 Higgins JP, Thompson SG: Quantifying heterogeneity in a meta-analysis. Stat Med 2002; 21:1539-1558.
16 Egger M, Davey SG, Schneider M, Minder C: Bias in meta-analysis detected by a simple, graphical test. BMJ 1997;315:629-634.

-17 Halfdanarson T, Bamlet W, McWilliams R, Hobday T, Burch P, Petersen G: Risk factors for sporadic pancreatic neuroendocrine tumors (PNETs): updated results from a singlecenter case control study. Neuroendocrinology 2012;96:34.

18 Halfdanarson TR, Bamlet WR, Hobday TJ, McWilliams RR, Petersen GM: Risk factors for sporadic pancreatic neuroendocrine tumors (PNETs): a single-center case control study. Pancreas 2010;39:273.

19 Cote ML, Schenk M, Schwartz AG, Vigneau FD, Kinnard M, Greenson JK, Fryzek JP, Ying
GS, Garabrant DH: Risk of other cancers in individuals with a family history of pancreas cancer. J Gastrointest Cancer 2007;38:119126.

20 Turati F, Negri E, La Vecchia C: Family history and the risk of cancer: genetic factors influencing multiple cancer sites. Expert Rev Anticancer Ther 2014;14:1-4.

21 Ito T, Sasano H, Tanaka M, Osamura RY, Sasaki I, Kimura W, Takano K, Obara T, Ishibashi M, Nakao K, Doi R, Shimatsu A, Nishida T, Komoto I, Hirata Y, Nakamura K, Igarashi $\mathrm{H}$, Jensen $\mathrm{RT}$, Wiedenmann $\mathrm{B}$, Imamura M: Epidemiological study of gastroenteropancreatic neuroendocrine tumors in Japan. J Gastroenterol 2010;45:234-243. 